\title{
Single-Use vs Reusable Ureteroscopes in Horseshoe Kidney Stones
}

\author{
Bogdan GEAVLETE ${ }^{\mathrm{a}}$, , Razvan POPESCU ${ }^{\mathrm{b}}$, Valentin IORDACHE ${ }^{\mathrm{a}, \mathrm{b}}$, Petrisor GEAVLETEa, b
}

aSanador Hospital, Bucharest, Romania

b"Saint John" Emergency Clinical Hospital, Department of Urology, Bucharest, Romania

\begin{abstract}
Introduction: Horseshoe kidney (HSK) is one of the most frequent renal malformations which appears to present an increased risk of stone formation caused by abnormal urine drainage. This study aims to compare the results of single-use flexible ureteroscopy (SUfURS) vs reusable devices (RfURS) with holmium laser in treating stones in HSK cases.

Material and method: Between February 2017 and June 2021, 29 patients diagnosed with renal stone disease and horseshoe kidney were retrospectively analyzed. Subjects were divided into two groups: Group 1 (14 patients) undergoing SUfURS and Group 2 (15 patients) operated with RfURS devices. We analyzed the mean stone burden, operation time, stone free rate and complications. The surgical equipment was represented by the SUfURS PU3022 (Zhuhai Pusen Medical Technology) and RfURS URF-V2 (Olympus).

Results: The two groups had a similar mean stone burden: $22 \pm 6 \mathrm{~mm}$ (range 15-31 mm) for Group 1 and $24 \pm 7 \mathrm{~mm}$ (range 16-30 mm) for Group 2. The average operative time was better for Group 1 (86 $17 \mathrm{~min}$ ) vs Group $2(89 \pm 20 \mathrm{~min})$. The stone-free status was similar for both groups after the first session $(57.14 \%$ for Group 1 vs $53.33 \%$ for Group 2) and slightly in favor of Group 1 as compared to Group 2 (85.71\% vs $73.33 \%$, respectively) after the second session. The overall complication rate (Grades I, II and III) was almost similar in both groups, with a slightly prevalence for Group 1 (no major complications Grade IV and V).

Conclusions: Flexible ureteroscopy represents an effective alternative treatment technique for large stones in kidney abnormalities. single-use flexible ureteroscopy can be successfully used to treat patients with genetically renal malformations and its results may be slightly better than those provided by using RfURS devices.
\end{abstract}

Keywords: kidney stone, flexible ureteroscopy, horseshoe kidney, renal malformation, holmium laser, stone-free.

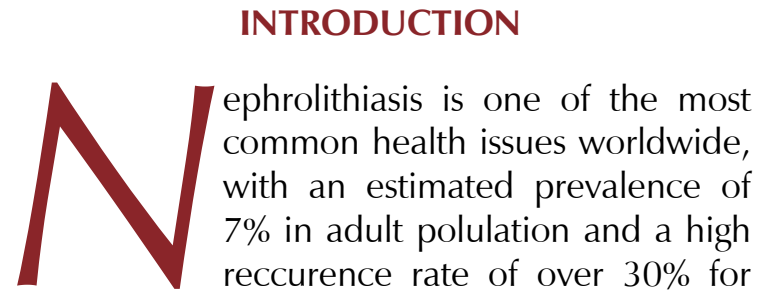

the next 10 years after a first episode $(1,2)$. Its continuously increasing prevalence is currently estimated to be up to $15 \%(3,4)$. Frequently men are more predisposed to develop lithiasis, with a $13 \%$ prevalence rate compared to $7 \%$ in women $(1,4)$.

Horseshoe kidney (HSK) is one of the most frequent malformations which appears to pre-

\footnotetext{
Address for correspondence:

Geavlete Petrisor, MD

Sanador Hospital, "Saint John" Emergency Clinical Hospital, Department of Urology, Bucharest, Romania

Sos. Vitan-Barzesti, 13, 042122, Bucharest, Romania

Email: geavlete@gmail.com
}

Article received on the $14^{\text {th }}$ of September 2021 and accepted for publication on the $8^{\text {th }}$ of December 2021 
sent an increased risk of stone formation. This renal fusion anomaly has an estimated prevalence of $0.25 \%$ in adult population. Studies revealed that about 1/400-1 600 of newborns are diagnosed with $\operatorname{HSK}(5,6)$. As a short anatomical description, this kind of pathology combines lower renal pole fusion and high placed ureter with abnormal position of the ureteropelvic junction (7). Urolithiasis has a prevalence of $20 \%-60 \%$ among HSK population. In most cases, stone related disease is caused by impaired renal drainage and different levels of obstruction $(5,8,9)$. Recurrent infections and metabolic causes are also associated with lithiasis development when discussing about renal malformation.

Advanced achievements in technology permitted the development of new generations of flexible ureteroscopes with improved deflection angle, small caliber, high quality image and retrograde management even for renal abnormalities reported good results in several studies $(11,12)$. Flexible ureteroscopy gained an important attention because it associated both high stone-free rates and significantly reduced risk of complications compared to other techniques.

As stated by the European Association of Urology (EAU), retrograde intrarenal approach represents one of the most important options for stones less than $2 \mathrm{~cm}$ (10). Valuable results were obtained when using this technique for treating renal calculi developed on renal malformations.

A new step in developing personalized treatment methods adapted to patients' characteristics is represented by the new generations of single use flexible ureteroscopes (SUfURS), which brings several advantages such as reduced sterilization and lack of repair for damaged devices (13). Single use flexible ureteroscopes have already proved their efficiency in treating stones located on normal renal anatomy.

The aim of this study is to compare the results of SUfURS and reusable flexible ureteroscopes (RfURS) on large dimension stone developed on horseshoe kidney malformation.

\section{MATERIAL AND METHODS}

The present study retrospectively analyzed 29 patients diagnosed with renal stone disease and HSK between February 2017 and November 2020. Stone characteristics and anatomical

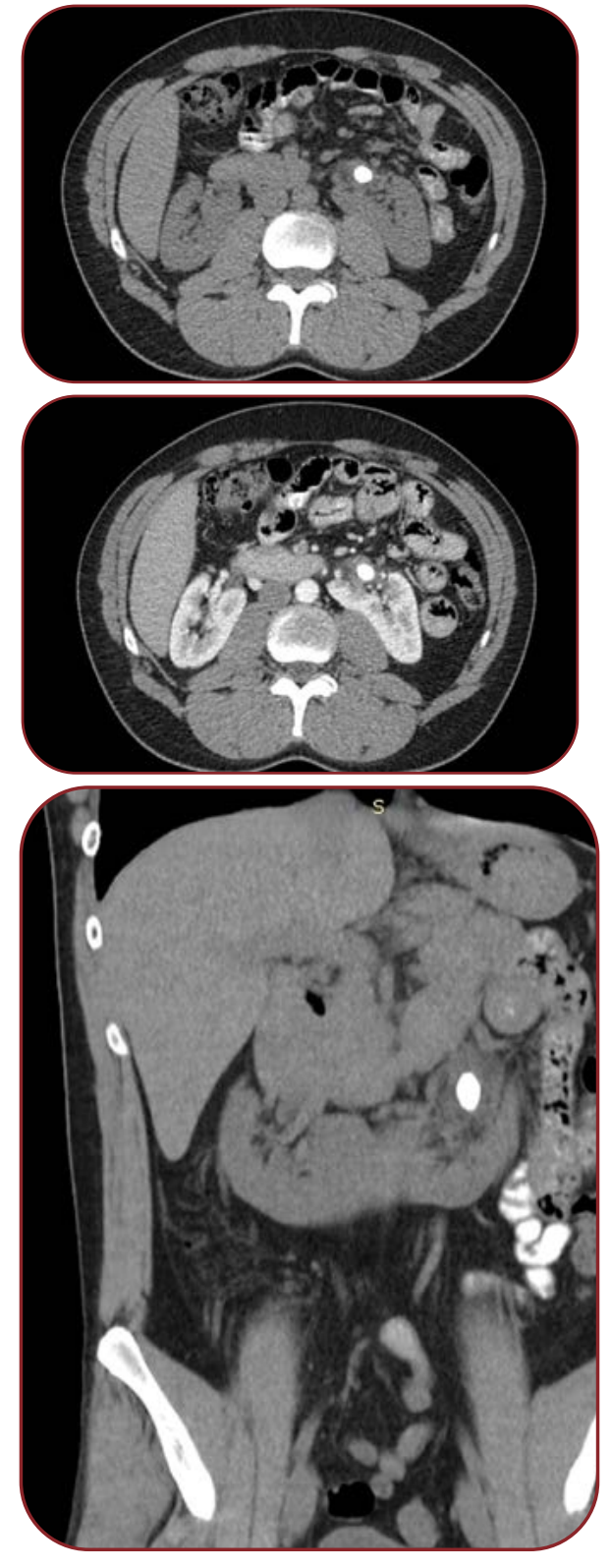

FIGURE 1. Sagittal and coronal computed tomography sections with and without contrast enhancement of a $2.15 \mathrm{~cm}$ renal stone

data were observed based on the computed tomography (CT) scan imaging archive. Stone burden was expressed measuring the largest diameter and surface area (SA) was calculated after measuring length and width with following formula: $\mathrm{SA}=\mathrm{I}^{\times} \mathrm{W}^{\times} \pi^{\times} 0.25$. For larger stones, more than one session of flexible ureteroscopy was necessary. Stone-free rate was evaluated after each session based on CT evaluation. Residual fragments were defined as more than $3 \mathrm{~mm}$ diameter.

Our patients were divided into two groups: Group 1 (14 patients), in which we used SUfURS, 


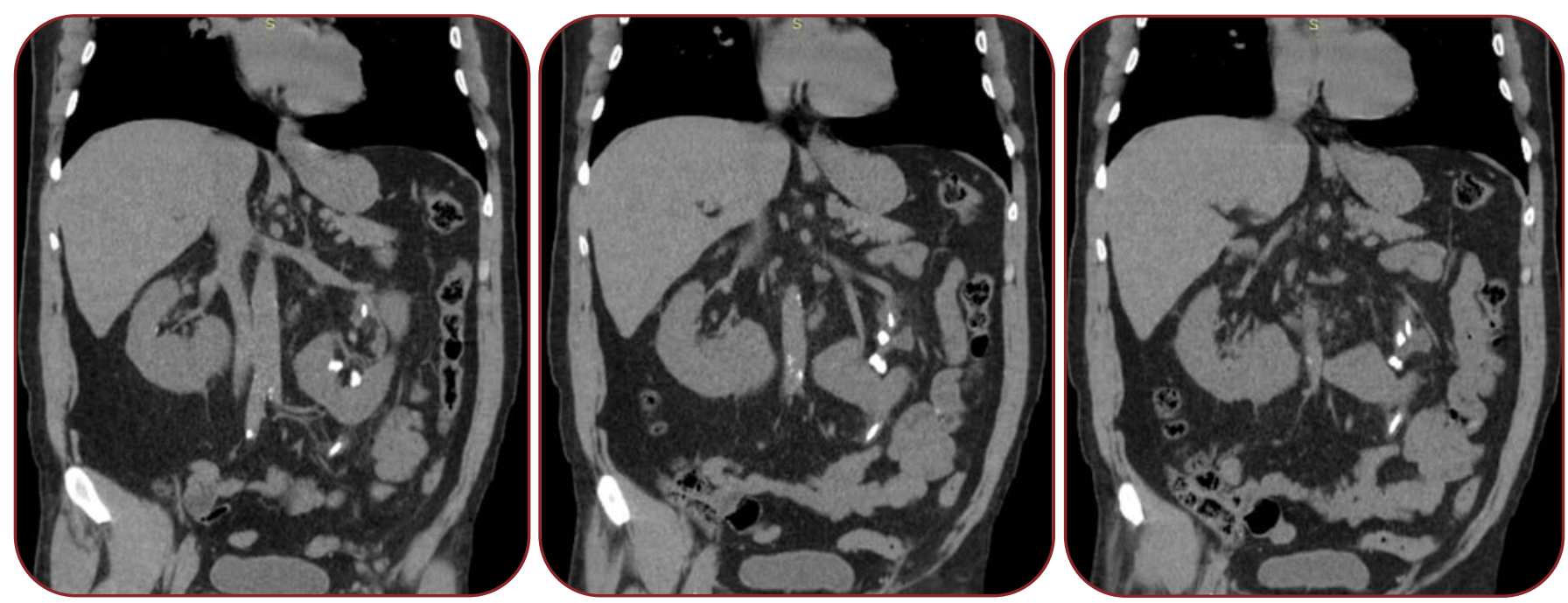

FIGURE 2. Native computed tomography scan sections of horseshoe kidney with multiple stone locations

and Group 2 (15 patients), in which we used RfURS.

\section{Surgical procedure}

Standard protocol was applied in all cases (lithotomy position and spinal anesthesia). The equipment included the SUfURS PU3022 (Zhuhai Pusen Medical Technology) and RfURS URF-V2 (Olympus).

Semirigid ureteroscopy was performed in all cases before placing the ureteral access sheath (10/12 Fr.). When the imagistic evaluation revealed possible difficulties in accessing the ureter, a double J stent was placed and maintained for one week until surgical approach.

The holmium laser was used based on standard manufacturer indications for both groups as follows: for dusting, low energy (0.5 J), high frequency $(50 \mathrm{~Hz})$ and long pulse; for pop-corning, high energy $(>1 \mathrm{~J})$, medium frequency $(10-50 \mathrm{~Hz})$ and long pulse; and for fragmenting, high energy $(>1 \mathrm{~J})$, low frequency $(<10 \mathrm{~Hz})$ and short pulse.

\section{Data analysis}

All collected data were obtained from the medical records and further processed and illustrated using Microsoft Excel and Word available on Microsoft Office 18.2008.12711.0 version.

\section{RESULTS}

Datients' characteristics revealed increased percentages for male population with an overall male to female ratio of 2.22 to 1 . Sub- jects' mean age was 45.6 years old in Group 1 and 47.3 in Group 2.

Mean stone burden had similar values in both groups: $22 \pm 6 \mathrm{~mm}$ (range 15-31 mm) for Group 1 and $24 \pm 7 \mathrm{~mm}$ (range 16-30 mm) for Group 2. Mean stone surface area $(\mathrm{SA})$ was similar in Group $1\left(287 \pm 42 \mathrm{~mm}^{2}\right.$, range 146-340 $\left.\mathrm{mm}^{2}\right)$ and Group $2\left(298 \pm 49 \mathrm{~mm}^{2}\right.$, range 151-374 $\mathrm{mm}^{2}$ ). Lower calyx was the most frequent location in both studied groups (Table 1). Stone relocation was successfully performed from lower calyx to renal pelvis or upper calyx in five (83.83\%) cases in Group 1 and four (66.66\%) cases in Group 2. Ureteral orifice was dilated in five $(17.34 \%)$ patients at the first attempt to place the access sheath.

Average operative time and significant fluoroscopy time were shown to have slight better values with single use devices (Table 2 ).

TA B LE 1. Stone data of our series of patients

\begin{tabular}{|l|l|l|l|l|}
\hline \multicolumn{2}{|c|}{ Stone burden } & Group 1 & Group 2 \\
\hline Stone status & \multirow{2}{*}{ Single } & & $22 \pm 6 \mathrm{~mm}$ & $24 \pm 7 \mathrm{~mm}$ \\
\cline { 3 - 5 } & & $8(57.14 \%)$ & $7(46.66 \%)$ \\
\cline { 3 - 5 } & & Pelvis & $2(14.28 \%)$ & $2(13.33 \%)$ \\
\cline { 3 - 5 } & & Upper calyx & $2(14.28 \%)$ & $1(6.66 \%)$ \\
\cline { 3 - 5 } & Middle calyx & $1(7.14 \%)$ & $1(6.66 \%)$ \\
\cline { 3 - 5 } & & Lower calyx & $3(21.42 \%)$ & $3(20 \%)$ \\
\cline { 3 - 5 } & Multiple & & $6(42.85 \%)$ & $8(53.33 \%)$ \\
\hline \multirow{3}{*}{ Laterality } & Right & & $6(42.85 \%)$ & $9(60 \%)$ \\
\cline { 2 - 5 } & Left & & $6(40 \%)$ \\
\hline
\end{tabular}


TAB LE 2. Operative details and complications

\begin{tabular}{|l|l|l|l|}
\hline \multicolumn{2}{|c|}{} & Group 1 & Group 2 \\
\hline Average operative time & & $86 \pm 17(\mathrm{~min})$ & $89 \pm 20(\mathrm{~min})$ \\
\hline Average fluoroscopy time & & $60.4(\mathrm{sec})$ & $82.1(\mathrm{sec})$ \\
\hline Hospitalization & & $28 \pm 4$ (hours) & $26 \pm 6($ hours) \\
\hline Complications (Clavien-Dindo) & Grade I & $3(13.04 \%)$ & $2(7.69 \%)$ \\
\cline { 2 - 4 } & Grade II & 0 & $3(11.53 \%)$ \\
\cline { 2 - 4 } & Grade IIIa & $1(4.34 \%)$ & 0 \\
\cline { 2 - 4 } & Total & $4(17.39 \%)$ & $5(19.23 \%)$ \\
\hline
\end{tabular}

Complication rates were evaluated using the Clavien-Dindo modified system. Overall complication rate (Grade I, II and III) was almost similar in both groups, with a slightly higher prevalence in Group 1. There were no major complications (Grade IV and V) and hospitalization time differences between the two groups (Table 2).

The stone-free status after first ureteroscopy was similar for both groups: $57.14 \%$ (Group 1) vs 53.33\% (Group 2) (Figure 3). After the second procedure we found a slightly higher stone-free rate in favor of Group 1: 85.71\% (Group 1) vs 73.33\% (Group 2). After the third procedure, percentages were again in favor of SUfURS devices. Computed tomography evaluation revealed residual fragments with stone burden range between 6 to $8 \mathrm{~mm}$ (one case in Group 1 and two cases in Group 2).

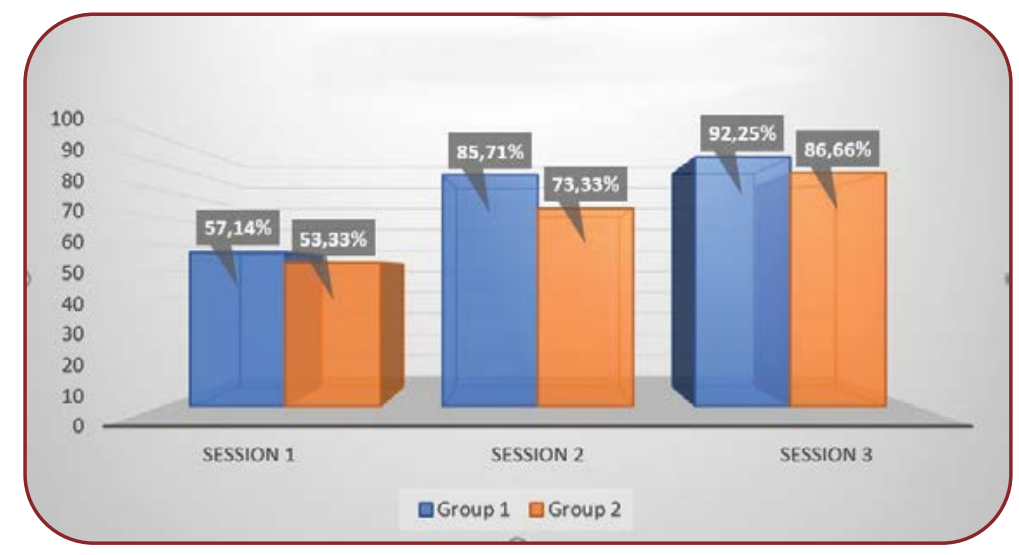

FIG URE 2. Stone-free rates between the two groups

All surgical procedures were performed by the same team consisting of two specialized endourologists with over 10-year experience in treatment of endourologic renal stone disease. $\square$

\section{DISCUSSION}

The worldwide prevalence of renal stones is continuously rising and proportionally, surgical interventions attempting to manage this pathology are also more frequently used (14). Surgical management often represents a challenging situation according to abnormal anatomy of the urinary tract (15). Horseshoe kidney is characterized by abnormal fusion of the lower poles and highly implanted ureter and mostly seem to affect male population (16). In our study, the male to female ratio was 2.22 to 1 compared to other studies that reported a $65 \%$ prevalence in males (17).

The actual surgical recommendations are mostly available for normal kidney anatomy and are usually related to dimension and location of the renal calculi.

Even though the surgical indications are clearly stated for patients with normal anatomy, some proper adapted management should be used for those with renal malformations such as horseshoe kidney, ectopic pelvic kidney and isolated rotation anomaly. Based on characteristics of each case, surgical approach is often personalized for optimal results.

The EAU guideline for urolithiasis states PNL as first option for stones bigger than $2 \mathrm{~cm}$ on the largest diameter (18). Even though the percutaneous approach is related to high stone-free rate, there are some major complications which can occur in 0.03 to $10 \%$ of cases (19). For HSK, PNL was successfully used to treat urolithiasis and literature findings reported a stone-free rate ranging from 77 to $93.2 \%$, which was associated with a slightly increased risk of complications from 14.3 to $29.2 \%$ (20-22). Besides complications including sepsis, bleeding, fever, urine leakage and pneumothorax, one major risk in HSK is represented by colonic injury caused by abnormal local anatomy. This is the reason why some researchers suggested a routine $\mathrm{CT}$ scan before PNL to observe a displaced or retrorenal position of the colon (23).

Shockwave lithotripsy (SWL) is recommended by EAU guidelines as one of the first options for treating intrarenal stones smaller than $2 \mathrm{~cm}$ (18). The reported stone free rate associated with extracorporeal therapy in HSK varies from 28 to $80 \%(24,25)$. These percentages are lower than those obtained when treating normal cases 
and is considered to be the main cause related to impaired renal drainage which affects stone clearance.

Retrograde intrarenal surgery is usually recommended for less than $2 \mathrm{~cm}$ calculi. In 1964, Marshall firstly introduced flexible ureteroscopes and Bagley and Rittenberg were the first who reported their results (26). The advanced technology and recent progresses made in developing new generation of high performance ureteroscopes led to an increasing number of procedures performed for renal stones. Flexible ureteroscopy is nowadays a more and more competitive alternative to PNL and SWL as it associates high stone free rates and less major complications than PNL. Some literature findings reported a $100 \%$ SFR for stone smaller than $2 \mathrm{~cm}$ and $85.1 \%$ for those bigger than $2 \mathrm{~cm}$ (27). The same study reported a $7.8 \%$ rate for minor complications and only $1.9 \%$ for major incidents.

In our study, RIRS was successfully used to treat renal calculi (even larger than $2 \mathrm{~cm}$ ). Retrograde approach seems to be safe in multiple or large stones compared to PNL technique, which may require multiple accessing tracts and having more complications. The same agreement was presented by Atis et al in their retrospective study (28).

Some studies revealed that a correctly placed access sheath improves scope maneuverability and "life". Weizer et al reported 50\% cases of correctly ureteral access sheath placement (15). According to Andreoni et al, UAS may be placed above the ureteropelvic junction in order to avoid injuries caused by scope reinsertion and to facilitate fragments retrieval (11). Singh et al reported that placing the access sheath beyond ureteropelvic junction significantly reduced scope movement and severely affected the possibility to explore the inferior calyx (29). In our study, access sheath was applied in both groups after firstly performing a semirigid ureteroscopy. In three cases, with tortuous ureter a double J stent insertion for one week before the surgical attempt was preferred to primarily placing the ureteral access sheath.

Weizer et al presented a $75 \%$ stone-free rate for a small series of malformations, four cases being HSK (15). Some years later, Molimar et al reported $88.2 \%$ stone-free rate after 1.5 session per patient, 17 cases being HSK (30). After analyzing 25 cases, Atis et al reported a 70\% stone- free rate after one session for a mean stone burden of $17.8 \pm 4.5 \mathrm{~mm}$ (28). More and more attempts to perform flexible ureteroscopy on anomalous kidney were made over the years. Ding et al. reported an $87.5 \%$ overall stone-free rate even for large calculi (6). In their report, the mean stone burden was $29 \pm 8 \mathrm{~mm}$ and the mean surface area $321 \pm 94 \mathrm{~mm}^{2}$, which were considered the largest dimensions until that time. Comparing to those reports, our study provided good overall results obtained when treating large stones over $2 \mathrm{~cm}$. Some differences for stonefree rate were identified when comparing the two selected groups favoring the single-use group. After all procedures the stone free rate was higher when using single-use devices.

Fluoroscopy exposure time represents an important aspect when accessing the upper urinary tract approach for both the patient and surgeon. In the present study, there were registered slightly better values for radiological exposure when using single-use ureteroscopes. The difference may be attributed to some specific characteristics. In contrast to reusable devices usage, the single-use technique always benefits from complete standard specification in mater of maneuverability maintained by the deflection angle. The optic direct view assured by these aspects is sometimes translated in shortened fluoroscopy time. After several usage, reusable devices lose part of their top characteristics and intraoperatively is sometimes needed a longer radiologic exposure for repositioning. Another important aspect of fluoroscopy time is related to stone characteristics. For example, in the single-use group, lower percentages of multiple stones were found. The small number of patients, mainly caused by the disease's rarity, makes it difficult to compare groups with the same specifications.

In our study, the mean operative time was slightly lower in Group 1 (86 $\pm 17 \mathrm{~min})$ than Group 2 (89 $\pm 20 \mathrm{~min})$, in which reusable devices were used. This is less than other studies reported when using reusable flexible ureteroscopy in HSK (eg, 106 and 126 min) (15, 30). Singh et al reported an average operative time of $74 \pm 21.2 \mathrm{~min}$ in their retrospective series (20).

\section{CONCLUSION}

- lexible ureteroscopy represents an effective alternative treatment technique for stones in 
kidney abnormalities such as horseshoe kidney, which associates high stone-free rates and low morbidity.

Single use ureteroscopes can be successfully used to treat patients with this malformation and seems to prove slightly better results than reusable devices.

Conflicts of interest: none declared.

Financial support: none declared.

Availability of data and materials: Datasets generated and/or analyzed during the current study are available from the authors on

reasonable request.

Ethical approval: This study was approved by the ethics committee of the Sanador Hospital and "Saint John" Emergency Clinical Hospital, Bucharest, Romania, and it was performed in accordance with the ethical standards of the 1964 Declaration of Helsinki and its later amendments.

Patient consent: Informed written consent was provided by each participant.

\section{$\boldsymbol{R}_{\text {fFerRences }}$}

1. Rule AD, Lieske JC, Li X, et al. The ROKS nomogram for predicting a second symptomatic stone episode. J Am Soc Nephrol 2014;25:2878 2886.

2. Lieske JC, Peña de la Vega LS, Slezak JM, et al. Renal stone epidemiology in Rochester, Minnesota: An update. Kidney Int 2006;69:760 764.

3. Stamatelou KK, Francis ME, Jones CA, et al. Time trends in reported prevalence of kidney stones in the United States: 19761994.

Kidney Int 2003;63:1817 1823.

4. Long LO, Park S. Update on nephrolithiasis management. Minerva Urol Nefrol 2007;59:317 325.

5. Weizer AZ, Silverstein AD, Auge BK, et al. Determining the incidence of horseshoe kidney from radiographic data at a single institution. J Urol 2003;170:1722 1726.

6. Ding J, Huang Y, Gu S, et al. Flexible ureteroscopic management of horseshoe kidney renal calculi. Int Braz J Urol 2015;41:683 689.

7. Natsis K1, Piagkou M, Skotsimara A, et al. Horseshoe kidney: A review of anatomy and pathology. Surg Radiol Anat 2014;36:517 26.

8. Muttarak M, Sriburi T. Congenital renal anomalies detected in adulthood. Biomed Imaging Interv J 2012;8:e7.

9. Otay AA, Sarhan O, Helaly AA, et al. Different management options for horseshoe kidney stones: Single center experience. J Urol 2016;1:e325

10. Desai MR, Sharma R, Mishra S, et al. Single-step percutaneous nephrolithotomy (microperc): the initial clinical report. J Urol 2011;186:140e5.

11. Andreoni C, Portis AJ, Clayman RV. Retrograde renal pelvic access sheath to facilitate flexible ureteroscopic lithotripsy for the treatment of urolithiasis in a horseshoe kidney. J Urol 2000;164:1290-1291.

12. Samodai L, Varga J, el-Seaghy AA, et al. Endoscopic removal of residual calculi from horse-shoe kidney and ureter. Acta Chir Hung 1989;30:219-224.

13. Tosoian JJ, Ludwig W, Sopko N, et al. The efect of repair costs on the profitability of a ureteroscopy program. J Endourol 2015;29:406-409.

14. Rukin N, Siddiqui Z, Chedgy E, et al. Trends in Upper Tract Stone Disease in England: Evidence from the Hospital Episodes Statistics (HES) Database. Urol Int 2017;98:391-396.

15. Weizer AZ, Springhart WP, Ekeruo WO, et al. Ureteroscopic management of renal calculi in anomalous kidneys. Urology 2005;65:265-269.

16. Pawar AS, Thongprayoon C, Cheungpasitporn W, et al. Incidence and characteristics of kidney stones in patients with horseshoe kidney: A systematic review and meta-analysis. Urol Ann 2018;10:87-93.

17. Al Otay A, Sarhan O, El-Tholoth HS, et al. Different managements of horseshoe kidney stones, any difference in the outcome? Urol Ann 2018;10:287-290.

18. Turk C, Knoll T, Petrik A, et al. Guideline on urolithiasis, 2010, pp 1-106. Available at: http://www.uroweb/gls/pdf/ Urolithiasis\% 202010.pdf.

19. Bassillote JB, Lee DI, Eichel L, et al. Ureteroscopes: flexible, rigid, and semirigid. Urol Clin N Am 2004;31:21-32.

20. Auge BK, Weizer AZ, et al. Percutaneous management of calculi within horseshoe kidneys. J Urol 2003;170:48-51.

21. Miller NL, Matlaga BR, Handa SE, et al. The presence of horseshoe kidney does not affect the outcome of percutaneous nephrolithotomy.

J Endourol 2008;22:1219-1225.

22. Symons SJ, Ramachandran A, Kurien A, et al. Urolithiasis in the horseshoe kidney: a single-centre experience. BJU Int 2008;102:1676-1680.

23. Skoog SJ, Reed MD, Gaudier FA Jr, et al. The posterolateral and the retrorenal colon: implication in percutaneous stone extraction. J Urol 1985;134:1100112.

24. Kurkali Z, Esen AA, Mungan MU. Effectiveness of extracorporeal shock-wave lithotripsy in the management of stone-bearing horseshoe kidneys. J Endourol 1996;10:13-15.

25. Serrate R, Regue R, Prats J, et al. ESWL as the treatment for lithiasis in horseshoe kidney. Eur Urol 1991;20:122-125.

26. Bagley DH, Rittenberg MH. Percutaneous antegrade flexible ureteroscopy. Urology 1986;27:331-334.

27. Breda A, Ogunyemi O, Leppert JT, et al. Flexible ureteroscopy and laser lithotripsy for multiple unilateral intrarenal stones. Eur Urol 2009;55:1190-1197.

28. Atis G, Resorlu B, Gurbuz C, et al. Retrograge intrarenal surgery in patients with horseshoe kidneys. Urolithiasis 2013;41:79-83.

29. Singh AG, Chhabra JS, Sabnis R, et al. Role of flexible uretero-renoscopy in management of renal calculi in anomalous kidneys: single-center experience. World J Urol 2017;35:319-324.

30. Molimard B, Al-Qahtani S, Lakmichi A, et al. Flexible ureterorenoscopy with holmium laser in horseshoe kidneys. Urology 2010;76:1334-1337. 